\title{
Perceived employer-related barriers and facilitators for work participation of cancer survivors: A systematic review of employers' and survivors' perspectives
}

Citation for published version (APA):

Greidanus, M. A., de Boer, A. G. E. M., de Rijk, A. E., Tiedtke, C. M., de Casterle, B. D., Frings-Dresen, M. H. W., \& Tamminga, S. J. (2018). Perceived employer-related barriers and facilitators for work participation of cancer survivors: A systematic review of employers' and survivors' perspectives. PsychoOncology, 27(3), 725-733. https://doi.org/10.1002/pon.4514

Document status and date:

Published: 01/03/2018

DOI:

10.1002/pon.4514

Document Version:

Publisher's PDF, also known as Version of record

Document license:

Taverne

Please check the document version of this publication:

- A submitted manuscript is the version of the article upon submission and before peer-review. There can be important differences between the submitted version and the official published version of record.

People interested in the research are advised to contact the author for the final version of the publication, or visit the DOI to the publisher's website.

- The final author version and the galley proof are versions of the publication after peer review.

- The final published version features the final layout of the paper including the volume, issue and page numbers.

Link to publication

\footnotetext{
General rights rights.

- You may freely distribute the URL identifying the publication in the public portal. please follow below link for the End User Agreement:

www.umlib.nl/taverne-license

Take down policy

If you believe that this document breaches copyright please contact us at:

repository@maastrichtuniversity.nl

providing details and we will investigate your claim.
}

Copyright and moral rights for the publications made accessible in the public portal are retained by the authors and/or other copyright owners and it is a condition of accessing publications that users recognise and abide by the legal requirements associated with these

- Users may download and print one copy of any publication from the public portal for the purpose of private study or research.

- You may not further distribute the material or use it for any profit-making activity or commercial gain

If the publication is distributed under the terms of Article $25 \mathrm{fa}$ of the Dutch Copyright Act, indicated by the "Taverne" license above, 


\title{
Perceived employer-related barriers and facilitators for work participation of cancer survivors: A systematic review of employers' and survivors' perspectives
}

\author{
M.A. Greidanus ${ }^{1}$ (D) | A.G.E.M. de Boer ${ }^{1}$ | A.E. de Rijk ${ }^{2}$ | C.M. Tiedtke ${ }^{2}$ | \\ B. Dierckx de Casterlé ${ }^{3}$ | M.H.W. Frings-Dresen ${ }^{1}$ | S.J. Tamminga ${ }^{1}$
}

${ }^{1}$ Academic Medical Center, University of Amsterdam, Department: Coronel Institute of Occupational Health, Amsterdam Public Health research institute, Amsterdam, The Netherlands

${ }^{2}$ Department of Social Medicine, Research Institute Primary Care and Public Health (CAPHRI), Faculty of Health, Medicine, and Life Sciences, Maastricht University,

Maastricht, The Netherlands

${ }^{3}$ Department of Public Health and Primary Care, Academic Center for Nursing and Midwifery, Katholieke Universiteit Leuven, Leuven, Belgium

\section{Correspondence}

M.A. Greidanus, MSc, Academic Medical Center, University of Amsterdam, Department: Coronel Institute of Occupational Health, Amsterdam Public Health research institute, Meibergdreef 9, 1100 DD Amsterdam, The Netherlands.

Email: m.a.greidanus@amc.nl

Funding information

Dutch Cancer Society, Grant/Award Number: UVA 2014-7153

\begin{abstract}
Objective: To identify employer-related barriers and facilitators for work participation of cancer survivors from the perspective of both employers and cancer survivors, and to synthesise these perceived barriers and facilitators to understand their perceived consequences.

Methods: A systematic review of qualitative studies focusing on employers' and cancer survivors' perspectives on the work participation of cancer survivors was performed. Four databases (MEDLINE, EMBASE, PsycINFO, and Business Source Premier) were systematically searched, and the quality of studies included was assessed using the CASP checklist. Perceived barriers and facilitators were extracted and synthesised to conduct a content analysis.

Results: Five studies representing the employers' perspectives and 47 studies representing the cancer survivors' perspectives were included. Employers perceived barriers and facilitators related to support, communication, RTW policies, knowledge about cancer, balancing interests and roles, and attitude. Survivors perceived barriers and facilitators related to support, communication, work environment, discrimination, and perception of work ability. The synthesis found that the employers' willingness to support can be understood by perceptions they have of the survivor, goals of the employer, and national or organisational policies. Employers require knowledge about cancer and RTW policies to be able to support survivors.
\end{abstract}

Conclusions: This review identified a plurality of and a large variety in perceived employerrelated barriers and facilitators for work participation of cancer survivors, which can be understood to be related to both employers' willingness and ability to support. There is a need for interventions targeting employers, with the aim of enhancing the sustainable work participation of cancer survivors.

\section{KEYWORDS}

cancer, cancer survivor, employer, employment, manager, oncology, qualitative, return to work, systematic review

\section{1 | BACKGROUND}

Cancer and its treatment have a significant impact on the lives of cancer survivors. ${ }^{1}$ Survivors can experience various levels of physical, emotional, financial, and social problems, including fatigue, depression, and anxiety, both during treatment and for years afterwards. ${ }^{2-5}$ These impairments can become persistent and chronic and may affect social functioning, including retaining employment., ${ }^{6,7}$
Cancer survivors consider returning to work as a key aspect of cancer survivorship..$^{7-9}$ Work gives them structure, a sense of "normalcy", distraction, the feeling of social belonging and financial security. ${ }^{7,8}$ As such, work can improve cancer survivors' quality of life. , $10^{-10}$ Although the majority of cancer survivors are actually able to return to work (RTW), during or after their treatment, several physical and psychosocial problems may hamper a sustainable work participation. ${ }^{7,11-13}$ Many survivors report concentration problems, memory deficits, and 
an overall impaired physical ability. ${ }^{13}$ Due to these problems, cancer survivors' ability to work and productivity level are often temporarily decreased. ${ }^{14,15}$ Several stakeholders, eg, employers, health care providers, social insurance physicians, colleagues, family, and friends can support cancer survivors to RTW or to stay at work and thereby minimise the impact of cancer on the working life of cancer survivors. ${ }^{16-18}$

Although the role of stakeholders upon RTW of cancer survivors varies among different countries (eg, because of differences in legislation), many studies across different countries acknowledge employers as one of the most important stakeholders during the RTW of cancer survivors. ${ }^{16,19-23}$ Employers are in the position to guide cancer survivors back to work and create good working conditions. ${ }^{19-22}$ Different studies have also emphasised that survivors perceive employers' social support, positive attitude, and understanding as important. ${ }^{19-23}$ At the same time, a discriminating or stigmatising employer may hinder work participation of cancer survivors or makes it more stressful for the survivor. ${ }^{24,25}$ In addition, survivors report that employers lack knowledge about how to deal with cancer in the workplace. ${ }^{20,26}$ Despite the important role of employers, interventions aiming at optimising the work participation of cancer survivors are usually patient oriented, and studies of the effectiveness of these interventions show inconclusive results at best. ${ }^{7,27,28}$ To optimise work participation of cancer survivors, interventions focused on optimising employer support during the RTW of cancer survivors might be "the missing link" and therefore much needed. ${ }^{29}$

To develop such interventions for employers, a deeper understanding of the role of employers during the RTW of cancer survivors is required. Qualitative research can provide such an indepth understanding. ${ }^{30,31}$ Therefore, there is a need to synthesise the knowledge acquired in qualitative studies about the work participation of cancer survivors and the role of employers in this. This synthesis may be helpful as input for future interventions targeting employers.

To achieve this aim, qualitative studies of either employers or cancer survivors were systematically reviewed and synthesised. By studying perspectives on employer-related barriers and facilitators of both employers and cancer survivors, differences in perceptions might also be identified. To this end, the following 3 research questions were addressed:

1. Which employer-related barriers and facilitators for work participation of cancer survivors were perceived by employers?

2. Which employer-related barriers and facilitators for work participation of cancer survivors were perceived by cancer survivors?

3. How can employer-related barriers and facilitators for work participation of cancer survivors be synthesised to understand the perceived consequences for work participation of cancer survivors?

In the following, the term "employer", refers to the case manager on the employer's side who is legally responsible for supporting the cancer survivor; for example, a line-manager, human resource manager (HR manager), or supervisor. In order to enhance readability, the term "employer" is used throughout the entire article.

\section{2 | METHODS}

The checklist of Preferred Items for Systematic Reviews (PRISMA Statement) was used to structure this review. ${ }^{32}$ In addition, the protocol of this review was registered in PROSPERO (registration number: CRD42016026526) to enhance reliability. ${ }^{33}$ To enhance the readability of the method section, the first research question will be referred to as the "employers" perspectives', while the second research question will be referred to as the "cancer survivors' perspectives".

\section{1 | Search strategy}

For both employers' and cancer survivors' perspectives, an extensive literature search was undertaken by the first author and checked by 3 co-authors (ST, MFD, AdB) and an experienced clinical librarian. The following databases were searched: MEDLINE (PubMed), EMBASE (Ovid), PsycINFO (Ovid), and Business Source Premier (EBSCOhost).

For the employers' perspectives, medical subject terms (MeSH Terms) and title and abstract words (TIAB) related to "employer", "work participation", "cancer", and "qualitative studies" were combined, each optimised for the different databases (Appendix A; see online supplemental materials). For the cancer survivors' perspectives, the same search was used, except for terms related to "employer", which were omitted. Both searches used filters to limit all articles to those with a publication date between January 2005 and December 2016, written in English or Dutch and available in full text. The time frame was chosen because of changes in the labour market and improvements in cancer treatment, which makes older studies on experiences of employers and cancer survivors less relevant. ${ }^{1,34}$

\subsection{Article selection}

The inclusion criteria for both perspectives were: (1) an abstract was available, (2) the article was published in a peer-reviewed journal, (3) a qualitative research design had been used (ie, open or semistructured interviews or focus groups, or an observational study), and (4) the article identified at least 1 employer-related barrier or facilitator for work participation of cancer survivors. For the employers' perspectives, the study population had to include employers, (line-) managers, supervisors, or HR managers, while the study population for the cancer survivors' perspectives had to include cancer survivors. The applied definition of a barrier and a facilitator were: behaviour, attitude, or perception of the employer that was perceived to hinder (barrier) or enhance (facilitator) sustainable work participation of a cancer survivor. Because employers do not have official duties with respect to the RTW of cancer survivors who do not have an employment contract, the cancer survivors were limited to those with a temporary or permanent employment contract on part-time, full-time, or flexible basis.

Article selection was performed in 2 rounds. Firstly, title and abstract screening was performed by 2 authors per article (MG and $\mathrm{ST}, \mathrm{AdB}$, or MFD). Secondly, full texts were read by 2 authors (MG and ST) and excluded if 1 or more of the inclusion criteria were not met. In the case of disagreement during the article selection, decisions were made at a meeting of 4 authors (MG, ST, AdB, and MFD). 


\section{3 | Quality assessment}

Two authors per article (MG and CT or AdR) assessed the quality of the articles included, using the Critical Appraisal Skills Programme (CASP) checklist. $^{35}$ In the case of disagreement, decisions were made at a meeting of 3 authors (MG, CT, and AdR). To avoid conflicts of interest, if 1 of the authors was the first author of an included study, this author was not involved in the quality assessment of this particular study. Regardless of their quality, all studies were included.

\section{4 | Data extraction}

Data were extracted by the first author using a predesigned extraction table which included study characteristics (first author, year of publication, country, participant characteristics, and data collection) and outcomes (perceived barriers and facilitators) (Appendices B and D; see online supplemental materials). The outcomes were only extracted from "results" or "findings" sections, with minimised author interpretation. The data extraction was checked by a second author (ST), and in the case of disagreement, decisions were made at a meeting of 4 authors (MG, ST, AdB, and MFD).

For those studies that included mixed populations (eg, employers, occupational physicians, and cancer survivors), only those perceived barriers and facilitators which clearly belonged to either the employers' perspectives or the cancer survivors' perspectives were extracted. In case of doubt, the corresponding author was approached for clarification.

\section{5 | Synthesis of results}

The Resource Dependence Institutional Cooperation Model (RDIC model) was adjusted and used to synthesise and analyse findings (Figure 1). ${ }^{36}$ This model was chosen because it enables the evaluation of employer support on several levels, which may contribute to a more comprehensive understanding of employer support. It is assumed that employer support (factor level 1) may be perceived as affecting sustainable work participation of cancer survivors (outcome) either negatively (barrier) or positively (facilitator). The level and type of employer support can be understood from concepts of factor level 2 (employers' willingness and ability to support) and factor level 3 (goals, resources, dependence, perceptions, and institutions).

The perceived barriers and facilitators extracted were synthesised in multiple stages to conduct a content analysis. The first stage consisted of author interpretation of the perceived barriers and facilitators. In the second stage, based on this interpretation, the barriers and facilitators were divided among the different concepts of factor level 1, 2, and 3 of the adjusted RDIC model using the MAXQDA (VERBI GmbH, Berlin, Germany) qualitative data analysis software package. In the third stage, within the different concepts of the adjusted RDIC model, the barriers and facilitators of more or less corresponding topics were divided into different subcategories. Finally, to clarify the outcomes, similar barriers and facilitators were merged at a certain level of abstraction without losing the essence of each barrier and facilitator. The interpretation, distribution, categorisation, and merging were performed by the first author in consultation with 2 authors who were familiar with the RDIC model (ST and AdR). In the case of disagreement at any stage of the data synthesis, decisions were made at a meeting of all authors.

\section{3 | RESULTS}

\section{1 | Employers' perspectives}

\subsection{1 | Studies included}

A total of 284 records were identified on the employers' perspectives (Figure 2). After removing duplicates, 212 were screened on title and abstract, of which 207 were excluded. The remaining 5 studies met all inclusion criteria. ${ }^{16,25,37-39}$ Two studies described results using the same data, but both were included because supplementary barriers and facilitators were extracted from both studies. ${ }^{25,39}$ The studies were conducted in Belgium ( $n=2)$, Canada $(n=2)$, and Australia $(n=1)$. The total sample size of all studies included was 43 and consisted of several occupations on the employers' side (ie, HR manager, department manager, chief executive officer, and rehabilitation team leader). All studies used rigorous data analysis and generally scored good on the CASP quality assessment (Appendix C; see online supplemental materials).

An overview of all characteristics of the studies included and employer-related barriers and facilitators extracted from each study on the employers' perspectives is shown in Appendix B (see online supplemental materials).

\subsection{2 | Perceived barriers and facilitators}

\section{Support}

Offering support during the entire duration of the illness was perceived by employers as a facilitator for work participation of cancer survivors. ${ }^{25,37,39}$ This support could be either practical or emotional. Diverse possibilities were mentioned concerning practical support,

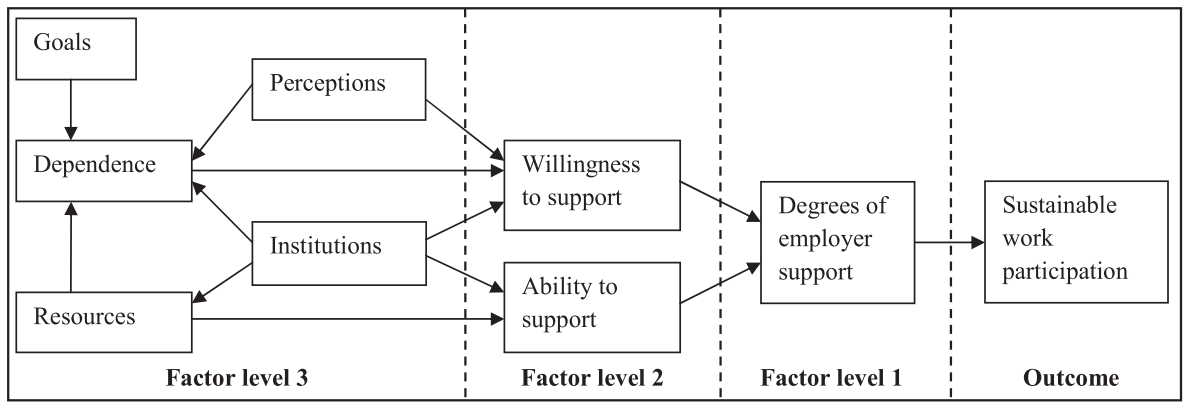

FIGURE 1 Adjusted version of the RDIC model of de Rijk et al ${ }^{36}$ 

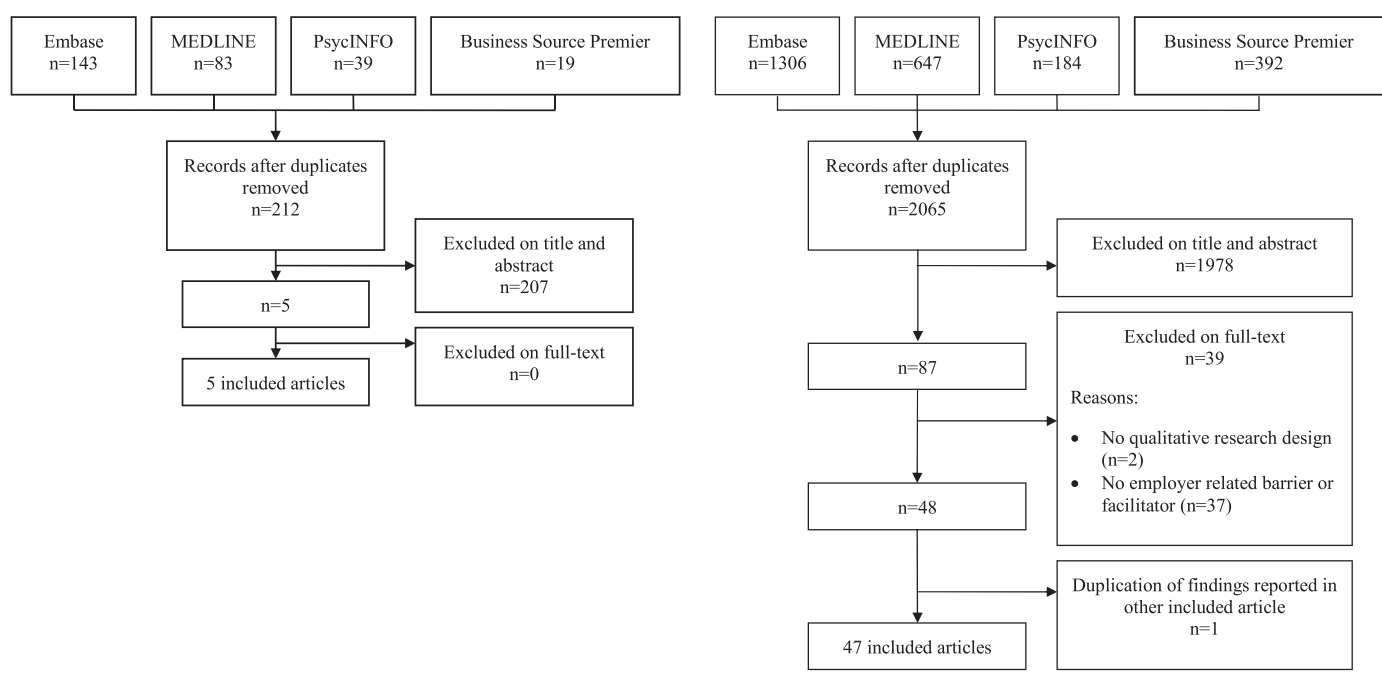

FIGURE 2 flowchart employers' perspectives (left chart) and cancer survivors' perspectives (right chart)

such as providing time off for medical appointments, reducing hours, sharing workloads with colleagues, and changing duties. ${ }^{37}$

\section{Communication}

Open communication between employer and survivors, and contact through "non-invasive channels", such as email or text messages, were also perceived as facilitators for survivors' work participation. ${ }^{16,37,38}$ When preparing the RTW, considering and discussing ways to communicate with the survivor during this process were also perceived as a facilitator for work participation of cancer survivors. ${ }^{39}$ However, employers also mentioned "respecting privacy", "not wanting to upset the survivor" and "avoiding victim connotations" as reasons to avoid cancer-related discussions. ${ }^{37}$ Nevertheless, avoiding these discussions was perceived by employers as a barrier for survivors' work participation. $^{37}$

\section{Policy}

Employers perceived the presence of RTW policies and protocols about possible arrangements for RTW as a facilitator for survivors' work participation. ${ }^{38}$ Being flexible with these policies was also perceived as a facilitator. ${ }^{16,37,38}$ Guiding the RTW process based on a standard set of principles, and a lack of information about the legal options concerning RTW, were both perceived as barriers. ${ }^{37,38}$

\section{Knowledge}

Lacking knowledge and experience with cancer survivors and insufficient medical information about the survivor were both perceived as barriers. ${ }^{25,38}$ Concerning external help for employers, insufficient support from specialists, and few opportunities to discuss RTW with fellow employers and company or other doctors were also perceived as barriers for work participation of cancer survivors. ${ }^{25,38}$ Employers found it difficult getting grip on the unpredictability of the course of the illness and absence, and experienced difficulties negotiating and managing the conditions of RTW, which were all perceived as barriers for survivors' work participation. ${ }^{16,25,37,38}$ Appointing a conduit or independent third party (eg, doctor or psychologist) was perceived as a facilitator. ${ }^{37}$

\section{Balancing interests and roles}

Employers experienced difficulties balancing the interests of the business, the survivor, colleagues, and a (temporary) replacement, which was perceived as a barrier for survivors' work participation ${ }^{16,37,38}$ : "When an employee wants to return to work part-time, with recommended adjustments to the job, this might create a dilemma for employers if they have arranged for a full-time and motivated replacement" (p. 244). ${ }^{16}$ In addition, wrestling with different roles (ie, human, empathetic role vs professional, more distant role) and difficulties judging the line between support and invasion of privacy were perceived as barriers ${ }^{16,37,38: ~ " Y o u ~}$ shouldn't actually ask: "what have you got" and yet you want to remain in touch during the period of sickness. So it's not straightforward ..." (p. 403). ${ }^{38}$

\section{Attitude}

Employers regarded an open attitude, showing real interest and commitment, and giving encouragement to the survivor as facilitators for cancer survivors' work participation 37,38: "I tried to have as much contact as possible with her (...) from my position, that's not a policy here or anything like that, (...) but because of my own involvement..." (p. 402). ${ }^{38}$

\section{2 | Cancer survivors' perspectives}

\subsection{1 | Studies included}

The search for studies on the cancer survivors' perspectives identified 2529 articles, of which 464 were duplications. Of the remaining 2065 articles, 48 met the inclusion criteria (Figure 2). One study duplicated the results of another study and was therefore excluded. In 2 instances, 2 studies described results using the same data, but both described supplementary barriers and facilitators and were therefore included. ${ }^{17,25,39,40}$ This resulted in a total of 47 studies, describing 45 different populations. ${ }^{15-17,20,24-26,29,37,39-76}$ Most studies were conducted in European $(n=25)$ or North-American $(n=15)$ countries. Nineteen studies focused only on breast cancer survivors, 16 included survivors of various cancer types, and the other studies included survivors of gynaecological $(n=3)$, head/neck $(n=2)$, haematological $(n=1)$, prostate $(n=1)$ or colon/rectal $(n=1)$ cancer, Hodgkin's disease or Non-Hodgkin's lymphoma $(n=1)$, or did not report the type of cancer 
$(n=3)$. The quality of these studies was generally average to good, despite 9 articles lacking a sufficiently rigorous data analysis (Appendix $\mathrm{E}$; see online supplemental materials).

An overview of all characteristics of the studies included and employer-related barriers and facilitators extracted from each study on the cancer survivors' perspectives is shown in Appendix D (see online supplemental materials).

\subsection{2 | Perceived barriers and facilitators}

\section{Support}

Cancer survivors perceived employer support during the entire duration of the illness and during RTW as a facilitator for their work participation. This support could be either practical (eg, adjusting working tasks, hours, place or demands, providing (temporary) assistance or providing time for reintegration and retraining), social/emotional (eg, understanding of survivor's situation, treating the survivor normally, maintaining survivor's privacy or showing commitment), or financial (eg, providing sick pay provision). Not providing such practical, social/emotional, or financial support was perceived as a barrier for cancer survivors' work participation.

\section{Communication}

Survivors perceived continuous, regular, and weekly contact as a facilitator, while a lack of communication or no communication at all was perceived as barrier for cancer survivors' work participation. ${ }^{17,25,49,52,54,73}$ Positive, respectful, and personal interactions were perceived as facilitators, while negative, poor, ambiguous, frightening, patronising, discouraging, and pressuring communication from employers were perceived by survivors as barriers for their work participation. ${ }^{17,24,26,43,45,47,59,61,66}$ Discussing a survivor's work plan was perceived as facilitating their work participation ${ }^{24,25,37,39,45,47,52,64}$ : "So I went and spoke with my manager (...) and we were able to sort out which projects, which teaching assignments, which tasks, which meetings I would have to miss due to my radiation treatments. And we looked at a transition plan for that longer period of time" (p. 1044). ${ }^{39}$ In addition, conversations about the survivor's limitations to RTW and possible work adjustments, keeping the survivor up to date, and asking how he/she is doing were also perceived by survivors as facilitating their work participation. ${ }^{24,25,37,39,45,47,52,61,64}$

\section{Work environment}

A positive work environment, which consists of a normal, stable or caring environment, was perceived as a facilitator for cancer survivors' work participation. ${ }^{20,43,45,48}$ A negative work environment, that is, a non-supportive, rigidly structured, competitive, or hard-nosed environment, was perceived as a barrier for cancer survivors' work participation. $^{20,40,43,56}$

\section{Discrimination}

Some survivors felt discriminated against by the employer as a result of their sickness; for example, when the employer asked the survivor to resign, changed, or terminated the work of the survivor, or denied a deserved promotion 39,53,59,65: "Suddenly my ex-boss was asking me to quit the company to become a freelance consultant (...) I must say that there is job discrimination" (p. 273). ${ }^{59}$

\section{Perception of work ability}

According to survivors, invisible physical changes (eg, fatigue, cognitive problems, adaptation) caused employers to overestimate survivors' abilities, have unrealistic expectations, or have a lack of understanding of long-term side effects, which they perceived as barriers for their work participation. ${ }^{20,24,26,45,54,65}$ As 1 survivor quoted their employer: "You look wonderful. You look fantastic. I can't understand why you're tired" (p. 293). ${ }^{65}$ By contrast, an employer with a negative attitude about a survivor's work ability was also perceived by survivors as a barrier for their work participation. ${ }^{20,39,70,71,73,76}$

\subsection{Synthesis of perceived barriers and facilitators}

All perceived barriers and facilitators for work participation of cancer survivors, merged and divided into different subcategories and concepts of the adjusted RDIC model, are shown in Appendix F (see online supplemental materials). As a result of the greater number of articles reporting barriers and facilitators from the cancer survivors' perspectives, these barriers and facilitators were merged at a higher level of abstraction compared with those perceived by employers.

\section{Degrees of employer support}

Practical and social/emotional employer support were perceived as facilitators for work participation by both employers and survivors. In addition, survivors perceived financial support as a facilitator. Both employers and cancer survivors perceived communication as important, with regular and positive communication perceived as facilitators and negative or a lack of communication perceived as barriers for cancer survivors' work participation.

\section{Willingness to support}

Cancer survivors mentioned that an employer who is willing to help and wants them back at work was a facilitator for their work participation. Some barriers and facilitators can also be considered to be related to employers' willingness to support. Regarding perceptions of the cancer survivors, having a good attitude, a good and long relationship with the survivor, and being able to observe and recognise the survivor's work ability may enhance an employer's willingness to support. By contrast, a negative attitude, a strained relationship with the survivor, and overestimating survivors' work ability may have negative consequences on an employer's willingness. Conflicting goals of the employer and a lack of external help were the specific perceived barriers decreasing the employer's feeling of dependence on the survivor, which may in fact hinder an employer's willingness to support a cancer survivor. Finally, an employer's willingness to support could also be understood as being the consequence of the culture and policy that is experienced.

\section{Ability to support}

Employers and cancer survivors reported that employers needed more knowledge about cancer. Employers appeared to lack knowledge about cancer in general and information about the illness of the specific survivor, which may hinder their ability to support. Secondly, (organisational) RTW policies and laws offered structure to the complex process, while a lack of legal options concerning RTW was perceived as a barrier. 


\section{4 | DISCUSSION}

\section{Aim and general findings}

The aim of this systematic review was to identify perceived employerrelated barriers and facilitators for work participation of cancer survivors and to synthesise these barriers and facilitators to understand the perceived consequences for work participation of cancer survivors. Five studies of employers' perspectives and 47 of cancer survivors' perspectives were included. A plurality of and a large variety in barriers and facilitators for work participation of cancer survivors were identified. The synthesis shows that work participation of cancer survivors is perceived to be influenced by both the employer's willingness and ability to support the cancer survivor. This willingness and ability of the employer can be understood to be a consequence of underlying barriers and facilitators.

\section{Clinical implications}

It was suggested that employers may play an essential role for work participation of cancer survivors, with supervisor support being an important RTW facilitator. ${ }^{23}$ The importance of employer support for work participation of cancer survivors was also perceived by both employers and survivors in the current review. Nevertheless, the diversity of the perceived barriers and facilitators related to employer support indicates the complexity of giving cancer survivors adequate support. Insofar as some perceptions of cancer survivors regarding employer support seem contradictory (eg, survivors mentioned both the need to be supported and the need to be treated normally in the workplace), giving cancer survivors adequate support is even more complex. ${ }^{53,63}$ In addition, some survivors perceived an employer who updated colleagues about their sickness as a facilitator, while others perceived such an employer as hindering their work participation. ${ }^{37}$ To enhance the work participation of cancer survivors, it is therefore recommended not to develop interventions with a "1-size-fits-all" approach.

To adjust employer support to survivors' individual preferences and requirements, effective employer-survivor communication seems to be a prerequisite. In a recent intervention study of workers with rheumatoid arthritis, a dialogue with the employer had a small but positive effect on employer support, as perceived by the workers. ${ }^{77}$ The purpose of this dialogue was to discuss obstacles at work and to achieve consensus about feasible solutions to address these obstacles. ${ }^{77}$ Employer-cancer survivor communication concerning the latter's needs and expectations was also perceived as a facilitator for work participation in the current review. In addition, 2 questionnaire studies of cancer survivors found a significant association between having a RTW meeting with the employer and a higher chance of being employed. ${ }^{6,78}$ Concerning the tone and quantity of employer-survivor communication, various barriers and facilitators for work participation were perceived by survivors. This suggests that employers may require certain skills to effectively attune the amount and tone of contact with the individual cancer survivor. Considering the importance and difficulty of employer-survivor communication, it is recommended that communication tools be developed and employers be given training to improve their communication skills, and thereby facilitate effective employer-cancer survivor communication, which might have a positive effect on a sustainable work participation of cancer survivors.
In addition to skills in communicating with the cancer survivor, our current review also revealed that employers need a certain amount of knowledge about the effects of cancer and its treatment to be able to support cancer survivors in the workplace. Even more, employers mentioned that they need specific information about the illness of the cancer survivor in order to get grip on the workability and absence of the survivor. ${ }^{16,25,37,38}$ National privacy-related legislations and social security systems might influence the amount of sickness specific information that survivors share with the workplace. Relatively low protective security systems may lead to lower levels of disclosure in order to prevent themselves from being discriminated and stigmatised at the workplace. ${ }^{39}$ A solution to the lack of sickness specific information for the employer might be to shift the focus of sharing the diagnosis to sharing the survivor's limitations in relation to work and opportunities for the survivor to participate in work. As such, the employer is provided with useful information to get grip on the cancer survivor's workability and to support the survivor at work effectively, with reduced chance of stigmatisation and discrimination at the workplace.

To our knowledge, international research on RTW interventions targeting employers is lacking. Several organisations offer interventions for employers through online or other material or face-to-face training (eg, the British MacMillan Cancer Support), but scientific evidence on the effectiveness of such interventions on work participation is lacking. ${ }^{7,79}$ Considering the important and complex role of employers during the RTW of cancer survivors and the lack of evidence-based interventions for employers, it is recommended that effective interventions be developed for employers who have to deal with cancer survivors in the workplace.

\section{Strengths and limitations}

The strengths of the current review lie in its comprehensive search in multiple online databases and its rigorous and multistage synthesis, which contributed to the high reliability of the outcomes. In addition, the inclusion of qualitative studies of employers and cancer survivors led to an extensive overview of the perceptions of both stakeholders.

Nevertheless, several limitations cannot be ignored. Firstly, the outcomes of this review were the perceived barriers and facilitators for work participation of cancer survivors. Cohort studies must confirm whether or not these perceived barriers and facilitators also act in the same manner in relation to the work participation of cancer survivors. Secondly, perceived barriers and facilitators may be influenced by the context of each particular study; for example, national legislation concerning the role and responsibility of employers. The provision of financial support was, for example, perceived as a facilitator for survivors' work participation. Analysing studies from which those facilitators were extracted revealed that they were all conducted in countries with relatively low levels of protection by the social security system, in terms of financial compensation for employees on sick leave (ie, Asia, the United Kingdom, and Ireland). ${ }^{41,44,54,59,69,73}$ Consequently, national and organisational policies should always be taken into account when using the current study as a basis for developing interventions to enhance work participation of cancer survivors. Finally, the adjusted RDIC model has not yet been validated, which may affect the internal validity of this review. However, the adjusted 
RDIC model was a helpful evaluation tool in the synthesis of perceived barriers and facilitators for work participation of cancer survivors, and thereby contributed to a deeper understanding of employer support.

\section{Suggestions for further research}

More research on employers' perspectives concerning their role and needs regarding work participation of cancer survivors is needed. Firstly, the factors that increase employers' willingness to support cancer survivors should be studied in future research. Secondly, a wider understanding of the social context at work and its influence on work participation of cancer survivors is also needed. For example, the behaviour of colleagues has been found to influence RTW outcomes of injured employees. ${ }^{80}$ The role of colleagues and their support needs during the sick leave and RTW of cancer survivors has, to our knowledge, not yet been investigated.

\section{Conclusions}

Our current review identified a plurality of and a large variety in employer-related barriers and facilitators for work participation of cancer survivors, as perceived by both employers and cancer survivors. This indicates the importance and complexity of the role of the employer during the RTW of cancer survivors. Work participation of cancer survivors was perceived to be influenced by both employers' willingness and ability to support a cancer survivor. This willingness and ability can be understood to be a consequence of underlying barriers and facilitators. There is a need for interventions targeting employers, with the aim of enhancing the sustainable work participation of cancer survivors.

\section{SPONSOR}

Dutch Cancer Society (grant number UVA 2014-7153).

\section{REGISTER}

PROSPERO (registration number: CRD42016026526).

\section{CONFLICT OF INTEREST}

The authors have declared no conflict of interest.

\section{ETHICS APPROVAL}

Not applicable.

\section{ORCID}

M.A. Greidanus (D) http://orcid.org/0000-0001-8953-8824

\section{REFERENCES}

1. Mehnert A, de Boer A, Feuerstein M. Employment challenges for cancer survivors. Cancer. 2013;119(Suppl 11):2151-2159.

2. Koch L, Jansen L, Herrmann A, et al. Quality of life in long-term breast cancer survivors-a 10-year longitudinal population-based study. Acta Oncol. 2013;52(6):1119-1128.

3. Williams K, Jackson SE, Beeken RJ, Steptoe A, Wardle J. The impact of a cancer diagnosis on health and well-being: A prospective, populationbased study. Psychooncology. 2016;25(6):626-632.

4. Jarrett N, Scott I, Addington-Hall J, et al. Informing future research priorities into the psychological and social problems faced by cancer survivors: A rapid review and synthesis of the literature. Eur J Oncol Nurs. 2013;17(5):510-520.

5. Asher A, Myers JS. The effect of cancer treatment on cognitive function. Clin Adv Hematol Oncol. 2015;13(7):441-450.

6. Cooper AF, Hankins M, Rixon L, Eaton E, Grunfeld EA. Distinct workrelated, clinical and psychological factors predict return to work following treatment in four different cancer types. Psychooncology. 2013;22(3):659-667

7. de Boer AG, Taskila TK, Tamminga SJ, Feuerstein M, Frings-Dresen $\mathrm{MH}$, Verbeek $\mathrm{JH}$. Interventions to enhance return-to-work for cancer patients. Cochrane Database Syst Rev. 2015;9: CD007569.

8. Stergiou-Kita M, Grigorovich A, Tseung V, et al. Qualitative meta-synthesis of survivors' work experiences and the development of strategies to facilitate return to work. J Cancer Surviv. 2014;8(4):657-670.

9. Wells M, Williams B, Firnigl D, et al. Supporting 'work-related goals' rather than 'return to work' after cancer? A systematic review and meta-synthesis of 25 qualitative studies. Psychooncology. 2013;22(6):1208-1219.

10. Tamminga SJ, Bultmann U, Husson O, Kuijpens JL, Frings-Dresen $\mathrm{MH}$, de Boer AG. Employment and insurance outcomes and factors associated with employment among long-term thyroid cancer survivors: A population-based study from the PROFILES registry. Qual Life Res. 2016;25(4):997-1005.

11. Mehnert A. Employment and work-related issues in cancer survivors. Crit Rev Oncol Hematol. 2011;77(2):109-130.

12. Steiner JF, Nowels CT, Main DS. Returning to work after cancer: Quantitative studies and prototypical narratives. Psychooncology. 2010;19(2):115-124.

13. Duijts SF, van Egmond MP, Spelten E, van Muijen P, Anema JR, van der Beek AJ. Physical and psychosocial problems in cancer survivors beyond return to work: A systematic review. Psychooncology. 2014;23(5):481-492.

14. Nieuwenhuijsen K, de Boer A, Spelten E, Sprangers MA, Verbeek JH. The role of neuropsychological functioning in cancer survivors' return to work one year after diagnosis. Psychooncology. 2009;18(6):589-597.

15. Munir F, Burrows J, Yarker J, Kalawsky K, Bains M. Women's perceptions of chemotherapy-induced cognitive side affects on work ability: A focus group study. J Clin Nurs. 2010;19(9-10):1362-1370.

16. Tiedtke C, Donceel $P$, Knops L, Désiron H, Dierckx de Casterlé B, de Rijk A. Supporting return-to-work in the face of legislation: Stakeholders' experiences with return-to-work after breast cancer in Belgium. J Occup Rehabil. 2012;22(2):241-251.

17. Nilsson M, Olsson M, Wennman-Larsen A, Petersson LM Alexanderson K. Return to work after breast cancer: Women's experiences of encounters with different stakeholders. Eur J Oncol Nurs. 2011;15(3):267-274.

18. Young AE, Wasiak R, Roessler RT, McPherson KM, Anema JR, van Poppel MN. Return-to-work outcomes following work disability: Stakeholder motivations, interests and concerns. J Occup Rehabil. 2005;15(4):543-556.

19. Amir Z, Wynn P, Chan F, Strauser D, Whitaker S, Luker K. Return to work after cancer in the UK: Attitudes and experiences of line managers. J Occup Rehabil. 2010;20(4):435-442.

20. Tamminga SJ, de Boer AG, Verbeek JH, Frings-Dresen $\mathrm{MH}$. Breast cancer survivors' views of factors that influence the return-to-work process-a qualitative study. Scand J Work Environ Health. 2012;38(2):144 +

21. Tiedtke C, de Rijk A, Dierckx de Casterlé B, Christiaens MR, Donceel P. Experiences and concerns about 'returning to work' for women breast cancer survivors: A literature review. Psychooncology. 2010;19(7): 677-683.

22. Nilsson MI, Petersson LM, Wennman-Larsen A, Olsson M, Vaez M, Alexanderson K. Adjustment and social support at work early after 
breast cancer surgery and its associations with sickness absence. Psychooncology. 2013;22(12):2755-2762.

23. Williams-Whitt $\mathrm{K}$, Bultmann $\mathrm{U}$, Amick $\mathrm{B}$, et al. Workplace interventions to prevent disability from both the scientific and practice perspectives: A comparison of scientific literature, grey literature and stakeholder observations. J Occup Rehabil. 2016;26(4):417-433.

24. Tiedtke C, Dierckx de Casterlé B, Donceel P, de Rijk A. Workplace support after breast cancer treatment: Recognition of vulnerability. Disabil Rehabil. 2015;37(19):1770-1776.

25. Stergiou-Kita M, Pritlove C, van Eerd D, et al. The provision of workplace accommodations following cancer: Survivor, provider, and employer perspectives. J Cancer Surviv. 2016;10(3):489-504.

26. Yarker J, Munir F, Bains M, Kalawsky K, Haslam C. The role of communication and support in return to work following cancer-related absence. Psychooncology. 2010;19(10):1078-1085.

27. Tamminga SJ, de Boer AG, Verbeek JH, Frings-Dresen MH. Return-towork interventions integrated into cancer care: A systematic review. Occup Environ Med. 2010;67(9):639-648.

28. Duijts S, Dalton SO, Lundh MH, Horsboel TA, Johansen C. Cancer survivors and return to work: Current knowledge and future research. Psychooncology. 2017;26(5):715-717.

29. Fenlon D, Reed E, Blows E, Scanlon K, Wray J, Dewey A. Moving forward: A qualitative research inquiry to inform the development of a resource pack for women following primary breast cancer treatment. J Psychosoc Oncol. 2015;33(1):85-105.

30. Schonfield IS, Mozzola JJ. Strengths and Limitations of Qualitative Approaches to Research in Occupational Health Psychology, in Research Methods in Occupational Health Psychology: Measurement, Design and Data Analysis. New York: Routledge/Taylor \& Francis Group; 2013:268-289.

31. Mazzola JJ, Schonfield IS, Spector PE. What qualitative research has taught us about occupational stress. Stress and Health: Journal of the International Society for the Investigation of Stress. 2011;27:93-110.

32. Moher D, Liberati A, Tetzlaff J, Altman DG, PRISMA Group. Preferred reporting items for systematic reviews and meta-analyses: The PRISMA statement. J Clin Epidemiol. 2009;62(10):1006-1012.

33. Chien PF, Khan KS, Siassakos D. Registration of systematic reviews: PROSPERO. BJOG. 2012;119(8):903-905.

34. Ekberg K, Pransky GS, Besen E, et al. New business structures creating organizational opportunities and challenges for work disability prevention. J Occup Rehabil. 2016;26(4):480-489.

35. Critical Appraisal Skills Programme (CASP); Making sense of evidence. Available from: http://www.casp-uk.net/.

36. de Rijk A, van Raak A, van der Made J. A new theoretical model for cooperation in public health settings: the RDIC model. Qual Health Res. 2007;17(8):1103-1116.

37. McKay G, Knott V, Delfabbro P. Return to work and cancer: The Australian experience. J Occup Rehabil. 2013;23(1):93-105.

38. Tiedtke C, Donceel P, de Rijk A, Dierckx de Casterlé B. Return to work following breast cancer treatment: The employers' side. J Occup Rehabil. 2014;24(3):399-409.

39. Stergiou-Kita M, Pritlove C, Kirsh B. The "Big C"-stigma, cancer, and workplace discrimination. J Cancer Surviv. 2016;10(6):1035-1050.

40. Nilsson MI, Olsson M, Wennman-Larsen A, Petersson LM, Alexanderson K. Women's reflections and actions regarding working after breast cancer surgery-a focus group study. Psychooncology. 2013;22(7):1639-1644.

41. Amir Z, Neary D, Luker K. Cancer survivors' views of work 3 years post diagnosis: A UK perspective. Eur J Oncol Nurs. 2008;12(3):190-197.

42. Ashing-Giwa KT, Padilla GV, Bohórquez DE, Tejero JS, Garcia M. Understanding the breast cancer experience of Latina women. J Psychosoc Oncol. 2006;24(3):19-52.
43. Blinder VS, Murphy MM, Vahdat LT, et al. Employment after a breast cancer diagnosis: A qualitative study of ethnically diverse urban women. J Community Health. 2012;37(4):763-772.

44. Ceilleachair AO, Costello L, Finn C, et al. Inter-relationships between the economic and emotional consequences of colorectal cancer for patients and their families: A qualitative study. BMC Gastroenterol. 2012;12:62

45. Dorland HF, Abma FI, Roelen CA, Smink JG, Ranchor AV, Bultmann U. Factors influencing work functioning after cancer diagnosis: $A$ focus group study with cancer survivors and occupational health professionals. Support Care Cancer. 2016;24(1):261-266.

46. Egan R, Llewellyn R, Wood S, et al. The Cancer Stories Project: Narratives of encounters with cancer in Aotearoa. New Zealand Psychooncology. 2016;25(3):300-307.

47. Frazier LM, Miller VA, Miller BE, Horbelt DV, Delmore JE. Cancerrelated tasks involving employment: Opportunities for clinical assistance. J Support Oncol. 2009;7(6):229-236.

48. Frazier LM, Miller VA, Horbelt DV, Delmore JE, Miller BE, Averett EP. Employment and quality of survivorship among women with cancer: Domains not captured by quality of life instruments. Cancer Control. 2009;16(1):57-65.

49. Groeneveld IF, de Boer AG, Frings-Dresen MH. Physical exercise and return to work: Cancer survivors' experiences. J Cancer Surviv. 2013;7(2):237-246.

50. Grunfeld EA, Cooper AF. A longitudinal qualitative study of the experience of working following treatment for gynaecological cancer. Psychooncology. 2012;21(1):82-89.

51. Grunfeld EA, Drudge-Coates L, Rixon L, Eaton E, Cooper AF. "The only way I know how to live is to work": A qualitative study of work following treatment for prostate cancer. Health Psychol. 2013;32(1):75-82.

52. Isaksson J, Wilms T, Laurell G, Fransson P, Ehrsson YT. Meaning of work and the process of returning after head and neck cancer. Support Care Cancer. 2016;24(1):205-213.

53. Johnsson A, Fornander T, Rutqvist LE, Olsson M. Factors influencing return to work: A narrative study of women treated for breast cancer. Eur J Cancer Care (Engl). 2010;19(3):317-323.

54. Kennedy F, Haslam C, Munir F, Pryce J. Returning to work following cancer: A qualitative exploratory study into the experience of returning to work following cancer. Eur J Cancer Care (Engl). 2007;16(1):17-25.

55. Knott V, Zrim S, Shanahan EM, et al. Returning to work following curative chemotherapy: A qualitative study of return to work barriers and preferences for intervention. Support Care Cancer. 2014;22(12): 3263-3273.

56. Lilliehorn S, Hamberg K, Kero A, Salander P. Meaning of work and the returning process after breast cancer: A longitudinal study of 56 women. Scand J Caring Sci. 2013;27(2):267-274.

57. Mackenzie CR. 'It is hard for mums to put themselves first': How mothers diagnosed with breast cancer manage the sociological boundaries between paid work, family and caring for the self. Soc Sci Med. 2014;117:96-106.

58. Main DS, Nowels CT, Cavender TA, Etschmaier M, Steiner JF. A qualitative study of work and work return in cancer survivors. Psychooncology. 2005;14(11):992-1004.

59. Mak AK, Chaidaroon S, Fan G, Thalib F. Unintended consequences: The social context of cancer survivors and work. J Cancer Surviv. 2014;8(2):269-281.

60. McGrath PD, Hartigan B, Holewa H, Skarparis M. Returning to work after treatment for haematological cancer: Findings from Australia. Support Care Cancer. 2012;20(9):1957-1964.

61. Mitchell T. Both sides of the couch: a qualitative exploration of the experiences of female healthcare professionals returning to work after treatment for cancer. Eur J Cancer Care (Engl). 2015;24(6):840-853.

62. Moffatt S, Noble E. Work or welfare after cancer? Explorations of identity and stigma. Sociol Health IIIn. 2015;37(8):1191-1205. 
63. Morrison TL, Thomas RL. Survivors' experiences of return to work following cancer: a photovoice study. Can J Occup Ther. 2014;81(3): 163-172.

64. Morrison TL, Thomas RL. Cancer survivors' concealment or disclosure of diagnosis: Implications for return to work. Work. 2015;52(3): 643-655.

65. Nachreiner NM, Dagher RK, McGovern PM, Baker BA, Alexander BH, Gerberich SG. Successful return to work for cancer survivors. AAOHN J. 2007;55(7):290-295.

66. Raque-Bogdan TL, Hoffman MA, Ginter AC, Piontkowski S, Schexnayder K, White R. The work life and career development of young breast cancer survivors. J Couns Psychol. 2015;62(4): 655-669.

67. Robinson L, Kocum L, Loughlin C, Bryson L, Dimoff JK. I wanted you to know: Breast cancer survivors' control of workplace communication about cancer. J Occup Health Psychol. 2015;20(4):446-456.

68. Sandberg JC, Strom C, Arcury TA. Strategies used by breast cancer survivors to address work-related limitations during and after treatment. Womens Health Issues. 2014;24(2):e197-e204.

69. Tan FL, Loh SY, Su TT, Veloo VW, Ng LL. Return to work in multiethnic breast cancer survivors-a qualitative inquiry. Asian Pac J Cancer Prev. 2012;13(11):5791-5797.

70. Tiedtke C, Dierckx de Casterlé B, de Rijk A, Christiaens MR, Donceel P. Breast cancer treatment and work disability: Patient perspectives. Breast. 2011;20(6):534-538.

71. Tiedtke C, de Rijk A, Donceel P, Christiaens MR, de Casterlé BD. Survived but feeling vulnerable and insecure: A qualitative study of the mental preparation for RTW after breast cancer treatment. BMC Public Health. 2012;12:538.

72. Tighe M, Molassiotis A, Morris J, Richardson J. Coping, meaning and symptom experience: A narrative approach to the overwhelming impacts of breast cancer in the first year following diagnosis. Eur $J$ Oncol Nurs. 2011;15(3):226-232.

73. Timmons A, Gooberman-Hill R, Sharp L. The multidimensional nature of the financial and economic burden of a cancer diagnosis on patients and their families: Qualitative findings from a country with a mixed public-private healthcare system. Support Care Cancer. 2013;21(1): 107-117.
74. Dewa CS, Trojanowski L, Tamminga SJ, Ringash J, McQuestion M, Hoch JS. Advice about work-related issues to peers and employers from head and neck cancer survivors. PLoS One. 2016;11(4): e0152944.

75. Duijts SF, van Egmond MP, Gits M, van der Beek AJ, Bleiker EM. Cancer survivors' perspectives and experiences regarding behavioral determinants of return to work and continuation of work. Disabil Rehabil. 2016;1-9.

76. Stepanikova I, Powroznik K, Cook KS, Tierney DK, Laport GG. Exploring long-term cancer survivors' experiences in the career and financial domains: Interviews with hematopoietic stem cell transplantation recipients. J Psychosoc Oncol. 2016;34(1-2):2-27.

77. van Vilsteren M, Boot CR, Twisk JW, et al. Effectiveness of an integrated care intervention on supervisor support and work functioning of workers with rheumatoid arthritis. Disabil Rehabil. 2016;1-9.

78. Mehnert A, Koch U. Predictors of employment among cancer survivors after medical rehabilitation-a prospective study. Scand J Work Environ Health. 2013;39(1):76-87.

79. Support, M.C. Information and resources for employers. 2016 [cited 2016 18-11-2016]; Available from: https://be.macmillan.org.uk/be/s715-information-and-resources-for-employers.aspx.

80. Dunstan DA, Maceachen E. A theoretical model of co-worker responses to work reintegration processes. J Occup Rehabil. 2014;24(2):189-198.

\section{SUPPORTING INFORMATION}

Additional Supporting Information may be found online in the supporting information tab for this article.

How to cite this article: Greidanus MA, de Boer AGEM, de Rijk $A E$, et al. Perceived employer-related barriers and facilitators for work participation of cancer survivors: A systematic review of employers' and survivors' perspectives. PsychoOncology. 2018;27:725-733. https://doi.org/10.1002/pon.4514 